\title{
The impact of the company's patents on the value of its brand
}

\author{
Vitaliy Ruposov ${ }^{1}$, Tuyana Bayaskalanova ${ }^{1}$, and Natalia Dneprovskaya ${ }^{2, *}$ \\ ${ }^{1}$ Irkutsk National Research Technical University, 664074, Lermontova str., 83, Irkutsk, Russia \\ ${ }^{2}$ Plekhanov Russian University of Economics, 117997, Stremyanny lane, 36, Moscow, Russia
}

\begin{abstract}
The approach to assessing the impact of the number of effective patents on inventions registered by the company on the value of its brand is considered in this paper. In current conditions of turbulent economic development, the issue of value of the objects of intellectual property created by the company is often raised, since the value of such an object can be higher than the funds contributed to the charter capital. For high-tech companies, this imbalance can persist in the maturity stage. All these parameters define the relevance of the research. In the paper, statistical analysis of the ten most expensive companies in the world is performed, and a model of links between the value of the company and the number of intellectual property objects is built, that has revealed the independence of the brand value of the company. Based on the received economic and mathematical parameters, created on the basis of statistical data, the conclusions have been generated.
\end{abstract}

\section{Introduction}

As the economy moves from information to post-information phase of development, the role of intangible assets for the effectiveness of companies is growing. Success of a company, its position on the market is more and more determined by the structure and composition of its intellectual property. On the preceding socio-economic stage, the stage of industrial economics, material resources and industrial production have been the critically important economic factors. However, at the current stage the share of intangible assets, such as patents for inventions, industrial models and trademarks is constantly growing in the cost value of a product or a service.

First of all, intangible assets include registered objects of intellectual property in a form of patents, industrial models and trademarks. The presence of intangible assets of a company in a form of the registered patents for invention and industrial models reflect, in fact, the innovation activity of a company. Thus, innovations represent results of research and development embodied products or services, their production or sales. Development of innovations is certainly an objective when companies use techniques and tools of the knowledge management [1]. When patenting an invention, the main requirements are novelty, inventive level and industrial applicability. Therefore, the invention should not only

* Corresponding author: dama83@ mail.ru 
be new and original but have a potential for the practical use. Based on that, we came to the conclusion that the patent activity of a company reflects its innovative activity.

Today, many countries and companies are trying to switch to the production of intangible intellectual products. Such a production is more flexible in its management and requires energy effective technologies. Because of the intellectual production, it is possible to reach "sustainable development".

\section{Formulation of the problem}

Transition to the more knowledge-based development model assigns problems of the valuation of results of intellectual activity in a new way. In this study, a task of defining the impact of one kind of intellectual assets to another kind, specifically, the influence of the intellectual property of a company in a form of patents on invention on the value of brand (a trademark) of a company is solved. In this paper, the solution of the issue of identification of dependence between the brand value, as an intangible asset, and the number of patents of the company is presented.

The purpose of the research is to identify and describe dependence between the two basic kinds of intellectual property of a company, including the number of effective patents for invention and value of its trademark.

\section{Research Methods}

For completeness of analysis of the influence of the number of patents on the brand value of a company, it is necessary to include the data on its capitalization in the analysis. Unfortunately, there is no single list of companies with indication of their value, and on this reason we will refer to several most influential lists created by the analysts of the market. The most known rating is published by the American edition of Forbes, which is called "the rating of 100 most expensive brands in the world" [2]. Forbes editors take into account the profits of companies over the past three years and the ratio of brand influence on profits in different industries.

There are some other ratings of brands of companies in accordance with their value. For example, the consultancy agency Interbrand that is a part of the American communication holding Omnicom in 2015 published its annual, the $16^{\text {th }}$ to the date, rating of 100 most expensive brands of the world. On the version of Interbrend, 6 of the 10 most expensive brands are represented by the high-tech sector. As in the Forbes rating, the $1^{\text {st }}$ one is the brand of Apple.

It is worth mentioning that the consultancy agency Interbrand evaluates the value of brands in accordance with its own patented methodology. The necessary condition for the company that is the owner of a brand is that it has to disclose its financial indicators and be public. Specialists of Interbrand calculate a share of revenue in intangible assets of a company, the power of a brand and risks connected with it. It is assumed that the stronger is the brand, the less are risks.

As the global practice shows, accounting for intangible assets can be the key to assessing the value of the brand, at that the methodology of the Interbrand is aimed [3]. It is evident from the comparison of the two ratings, that the value in accordance with the Interbrand methodology is higher than the value calculated on the methodology of Forbes. For example, let us take the company Apple. Today, its value, in accordance with the version of Interbrand, is $\$ 170.276$ billion that is by $43 \%$ higher than a year before. The market capitalization of the company Apple Inc. on the closure of trades on Friday, October 2, 2015 was equal to about $\$ 629.5$ billion. Thus, if we focus on the calculations of Interbrand, the value of the most 
expensive brand is $27 \%$ of its total market value. The difference of the more precise understanding of intangible assets can be seen, if we compare the valuations of the consultancy agency Interbrand and rating of Forbes, where Apple is valued as \$ 145.3 billion.

For the purposes of the presented research, we have used data of the World Organization of Intellectual Property, accessible in the database PatentScope and Global Design Database $[4,5]$.

\section{Findings}

\subsection{Evaluation of companies' patent activity}

The American company IBM is the global leader on the number of registered patents. Developers and inventors of the company received more than 73 thousand patents worldwide. The first patent for invention of this company is dated by 1909. IBM investments in research and development continue changing future of information technologies with the help of cognitive calculations and digital platforms.

Despite dynamic development of the sector of information technologies and appearance of the new actors on the IT market, IBM keeps its leading position on the number of effective patents for inventions. Jinni Rometty, the President and Head of the Board of Directors of IBM points out that "the leadership of IBM in the sphere of patents underlines our continued commitment to the strategy of scientific and technological research, which are to stimulate the progress in business and society", and tools created by the company help the customers to accelerate innovative processes in many sectors [6].

The Table 1 demonstrates the list of the ten major patentees in the USA in 2015-2017. High-tech companies of other countries, specifically, Japan and South Korea, are also among the leading patent holders.

Table 1. Rating of the largest patent holders of the effective patents for invention, on the information of the USA Patent Agency (USPTO).

\begin{tabular}{|l|c|c|c|c|}
\hline \multicolumn{1}{|c|}{ Organization } & Country & $\mathbf{2 0 1 5}$ & $\mathbf{2 0 1 6}$ & $\mathbf{2 0 1 7}$ \\
\hline IBM & USA & 7355 & 8090 & 9043 \\
\hline Samsung & $\begin{array}{l}\text { South } \\
\text { Korea }\end{array}$ & 5072 & 5521 & 5837 \\
\hline Canon & Japan & 4134 & 3285 & 3665 \\
\hline Qualcomm & USA & 2900 & 2925 & 2628 \\
\hline Google & USA & 2835 & 2842 & 2457 \\
\hline Toshiba & Japan & 2627 & 1555 & 1965 \\
\hline Sony & Japan & 2455 & 2184 & 2135 \\
\hline LG Electronics & $\begin{array}{l}\text { South } \\
\text { Korea }\end{array}$ & 2242 & 2430 & 2701 \\
\hline Intel & USA & 2048 & 2793 & 3023 \\
\hline Microsoft & USA & 1956 & 2410 & 2441 \\
\hline
\end{tabular}

It is necessary to mention that high-tech market and production of the high-tech goods and services is going all over the world. Manuel Kastells, the researcher of the information society, specifies that the major difference between the information and technological revolution and its historical predecessor is the fact that if previous technological revolutions remained on the limited territory for a long time, new information technologies nearly immediately embrace the space of the whole planet. This means immediate application to one's own development technologies created by the technological revolution that link the 
world through the information technology [8]. The analysis of correlation of the national (USA) and international applications for registration of the intellectual property objects by the leading technological companies shows that such companies as IBM and Qualcomm are interested in the international registration of their inventions. At the same time, such companies as Samsung and Canon focus on ensuring patent defense of their intellectual property in the USA.

Comparative analysis of the patent information indicates that the leaders are mostly the companies that produce high-tech electronics, and at the same time, the role of computer and Internet technologies is very high (IBM Google, Canon, Intel and Microsoft). IT receives high significance for creation of innovations in all kinds of economic activities. For example, artificial intelligence technologies and big data are used for the development of products and services with a high level of customization [9].

Meanwhile, the companies that produce consumer electronics have approached the leaders of the rating. The second place in the rating is occupied by Samsung. Toshiba, Sony, and LG Electronics that have high indicators on the number of patents registered on the territory of the USA, are also in the list. Due to the fact that the US market is one of the most attractive, the assessment of the patents registered in the USA has a high correlation with the global market. Registration of patents by the large producers is an important component of the activity of organizations, especially in the situation of constant patent wars.

For presentation of the full picture of the companies' patent activities, it is needed to include into analysis the patents for industrial models. The patents for industrial models protect companies' rights for the appearance of the product, including design of its individual elements. Design of the product is also the object of intellectual property of the company. The company Apple is well known not only by new high-tech solutions used for development its products but by their peculiar esthetics and ergonomics highly appreciated throughout the world. The analysis of correlations of the effective patents for industrial model in the USA and the in the world shows that such companies as IBM, Canon, and Samsung have more patents for design than for inventions among their intellectual assets. It is necessary to mention, that companies have more international design projects than the US national patents. It reflects the global market, on which the goods and services of the companies are presented.

\subsection{Analysis of the dependence of the companies' intangible assets}

Let us consider analysis between the brand value as an intangible asset, and the number of patents registered on the territory of the USA. For that, it is needed to create a pivot table referring to a number of patents and evaluation of the brand value. To smooth features of the evaluation, we will use the brand value as per the rating of the American Forbes magazine for the year 2016.

Based on the data of the Table 2, which represents companies of not only the high-tech sector, but also ones engaged in the production of consumer electronics, internet shops, telecommunication companies and producers of automobiles, we will conduct the analysis.

Table 2 The list of organizations-holders of the maximum effective patents for invention in the USA, and their brands value, according to the Forbes magazine, 2016.

\begin{tabular}{|l|r|r|r|r|}
\hline Organizations & $\begin{array}{c}\text { Patents for } \\
\text { inventions in } \\
\text { the USA }\end{array}$ & $\begin{array}{c}\text { USA } \\
\text { design } \\
\text { patents }\end{array}$ & $\begin{array}{c}\text { International } \\
\text { design patents }\end{array}$ & $\begin{array}{c}\text { Brand value, in } \\
\text { US dollars }\end{array}$ \\
\hline IBM & 9043 & 9531 & 13942 & 41.4 \\
\hline Samsung & 5837 & 9213 & 10423 & 36.1 \\
\hline Canon & 3285 & 415 & 531 & 7.1 \\
\hline Google & 2457 & 678 & 753 & 82.5 \\
\hline
\end{tabular}




\begin{tabular}{|l|r|r|r|r|}
\hline Sony & 2135 & 2685 & 3669 & 7.6 \\
\hline Intel & 3023 & 166 & 170 & 27.7 \\
\hline Microsoft & 2441 & 3729 & 5734 & 75.2 \\
\hline Apple & 2273 & 2129 & 2733 & 154.1 \\
\hline Toyota & 1932 & 1471 & 4786 & 42.1 \\
\hline GE & 1577 & 17265 & 21987 & 92.3 \\
\hline Cisco & 967 & 252 & 260 & 28.4 \\
\hline Honda & 1031 & 1886 & 4063 & 25.2 \\
\hline Ford & 1868 & 1584 & 1986 & 14.1 \\
\hline HP & 1304 & 826 & 855 & 13.8 \\
\hline Amazon & 1963 & 146 & 340 & 35.2 \\
\hline AT\&T & 946 & 18 & 69 & 7.1 \\
\hline Panasonic & 1338 & 1075 & 1511 & \\
\hline
\end{tabular}

Sources: 2017 Top 50 US, Global Design Database Patent Assignees [5, 9].

In the beginning, let us build the correlation field and define the correlation coefficient, that is, determine whether the relationship between the number of patents and the value of the brand is high.

Based on the results of the correlation coefficient calculation, the value of which has been determined in the amount of 0.0056 , we can conclude that there is no such a relationship. Correlation coefficient must be assessed with the help of indicator of error and reliability. The standard (an error) in the correlation coefficient is calculated by the formula:

$$
\sigma_{r}=\frac{1-r^{2}}{\sqrt{n}}
$$

In this case it is equal to 0.24 . This indicator is used for the calculation of reliability of the correlation coefficient that is calculated by the formula:

$$
\mu=\frac{|r|}{\sigma_{r}}
$$

Calculation of the correlation coefficient is considered reliable, if the indicator calculated by this formula will be more than 3 . In the opposite case, it is necessary to increase the number of measurements. For the calculation as above, the indicator was equal to 0.023 that do not testify its reliability. However, it is mentioned in the literature [10] that with very low correlation coefficients, reliability cannot be calculated. It is connected with the occasional use of this indicator for further regressive analysis.

If we build the regression equation, we will receive the following data (please refer to the Figure 1). 


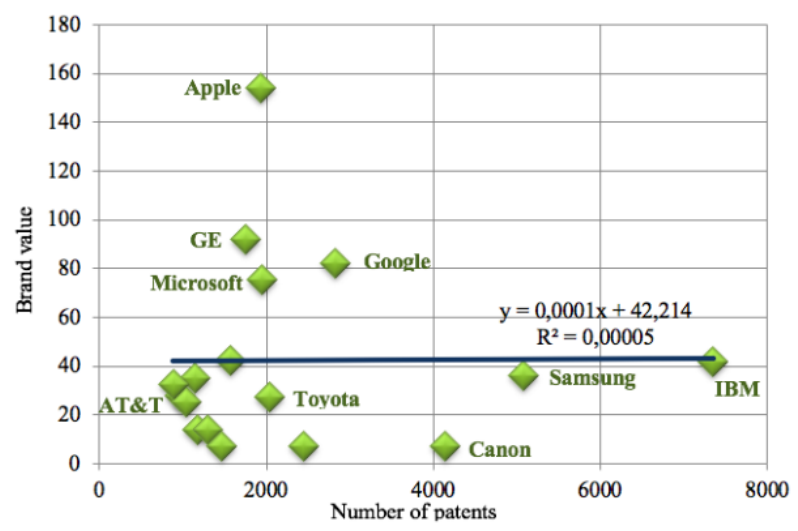

Fig. 1. The regression equation for correlation of the number of effective patents in the USA in the year 2015, and the brand value.

There is no dependence between the number of patents and brand value, and the determination coefficient is extremely low.

We have used data summarized in the Table 2 for identification of dependence between the effective design patents in the USA and international patents. Based on the calculation of the correlation coefficient, there is a very high relationship between the effective patents in the USA and international patents $(\mathrm{r}=0.99)$. On this reason, we will continue the analysis of dependence between the brand value and the number of the effective patents based on the indicators of international patents.

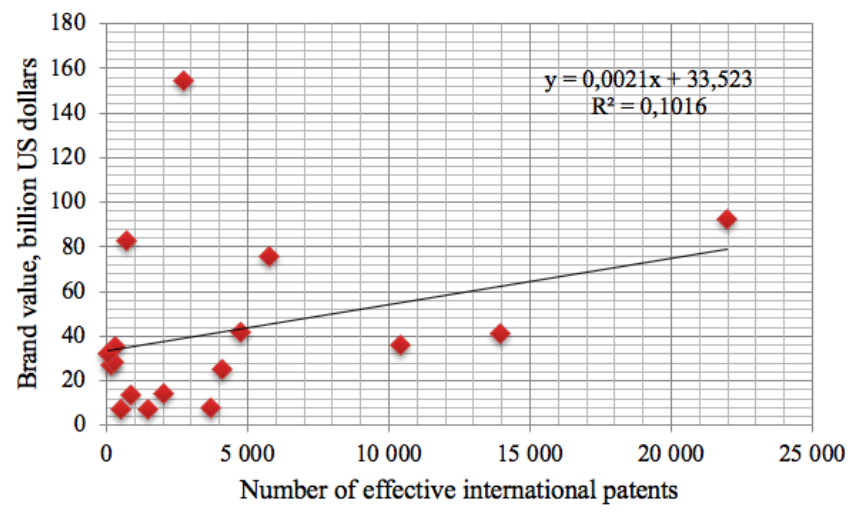

Fig. 2. The regression equation for correlation of the number of effective international design patents in the USA in 2018 with the brand value.

The dependence between the brand value and the number of effective international patents is very low, the correlation coefficient is 0.32 . However, it is higher than in the previous analysis that is connected with the lack of data for very expensive brands like TOYOTA or Coco-Cola, as well as with the fact that Table 2 presents mainly high-tech companies.

\section{Conclusion}

The conducted research has shown that high-tech companies prefer patenting as a means of protection of their intellectual property objects in a form of patents for inventions and industrial models. Herewith, a significant part in their intangible assets is the patents 
registered in the American patent agency. Situation with design patent is a bit different, since a significant part of these patents is registered by other national patent agencies. The difference in proportion between the patents effective in the USA and in other countries is determined by the differences in the patent legislation in different countries, as well as discrepancies in indicators of their socio-economic development.

To summarize the analysis, it can be concluded that for large companies the number of patents is not connected with the brand value. On this reason, not intellectual property but other brand parameters can represent here the key intangible asset. It is seen on the example of such companies as Coca-Cola, that is not an actor of high-tech business but has a very high value of its brand, or Facebook, that, despite its high dynamics brand value increase, puts in the first place not the creation of new high-tech products, but the expansion of the number of consumers of its services.

Based on the formulated above, we can make a conclusion that companies, which are going to increase their brand value should not rely on the creation of intellectual property. It is necessary to work in such directions as brand awareness, transnational character, positive history of development, etc. If the organization is engaged in high-tech business, and creation and registration of intellectual property is a means to take good positions on the market, then such a company should undertake additional efforts in order to increase its brand value and creation of good trademark to promote in the market.

The research has been carried out in the framework of the grant of the President of Russia for support of leading scientific schools, № HW-5449.2018.6 "A study of the digital transformation of economics."

\section{References}

1. N. Dneprovskaya, I. Shevtsova, T. Bayaskalanova \& I. Lutoev, Proceedings of the 15th European Conference on e-Learning, 159-165 (Academic Conferences and Publishing International Limited Prague, 2016)

2. Rating 100 of the most expensive brands in the world (http://www.forbes.ru/kompanii-photogallery/288451-samye-dorogie-brendy-mira2015-reiting-forbes/photo/1, 2015)

3. Interbrand named the most expensive brands in the world (http://www.rbc.ru/technology_and_media/05/10/2015/56124a4c9a79472e417cc30e , 2015)

4. PatentScope (http://www.wipo.int/patentscope/en/, 2017)

5. Global Design Database (http://www.wipo.int/reference/en/designdb, 2017)

6. IBM became the leader in the number of patents received for the 23rd consecutive year (http://www-03.ibm.com/press/ru/ru/pressrelease/48819.wss, 2016)

7. M. Y. Veselovsky, M. A. Izmailova, A. V. Bogoviz, S. V. Lobova, Y. V. Ragulina, Quality - Access to Success, 19(163), 30-36 (2018)

8. M. Kastells, The Internet galaxy (Oxford University Press, New York, 2001)

9. V. D. Urintsov, N. Dneprovskaya, Smart digital features (Netherlands, 2014)

10. 2017 Top 50 US Patent Assignees (https://www.ificlaims.com/rankings/rankings-top50-2017.htm, 2017)

11. V. L. Ruposov, Forecasting economic indicators (IGNITU, Irkutsk, 2011)

12. M. Y. Veselovsky, M. A. Izmailova, A. V. Bogoviz, S. V. Lobova, A. N. Alekseev, Quality - Access to Success, 19(162), 60-66 (2018) 